\title{
The Cost Of CMM Deployment In A Conventional IT Organization: A Field Study
}

Roshan Pinto, Carsley Corporation

Dan Shoemaker (E-mail: shoemadp@udmercy.edu), University of Detroit Mercy Gregory W. Ulferts, (Email: ulfertgw@udmercy.edu), University of Detroit Mercy Patrick Wirtz (E-mail: wirtzpt@udmercy.edu),, University of Detroit Mercy

\begin{abstract}
Over the past decade the software industry has periodically tried to upgrade its business performance by deploying strategic infrastructure frameworks based on expert models. Each of these schemes is aimed at organizing software work along the lines of commonly understood best practice. Their goal is to optimally align the policies and practices of the IT function so that they directly support and further the purposes and goals of the overall business operation (Lewis, 2001).

Although there are no authoritative statistics, arguably one of the most popular approaches is the Software Engineering Institute's (SEI) Capability Maturity Model (CMM v1.1) moreover it is certainly the framework of choice for the U.S. software industry. It was developed out of the research of Watts Humphrey and the Mitre Corporation and was first published by SEI in 1987 (Humphrey, 87a). Operationally, it is designed to advance the software organization's processes through five stages, or levels, of increasingly effective performance ranging from Chaos (At the initial end) to Optimized (at the high end). The organization adds best practices at each level, which both underwrites improved performance at that particular stage, as well as leverages advancement to the next stage.
\end{abstract}

The problem is that the "best practices" deployed by CMM are both generic and externally (from the company's perspective) defined. Consequently they require a complicated and expensive implementation process to specifically tailor the model for each organizational situation. Since the costs of this are concrete and in the near term and the benefits are (to some extent) intangible and long run, the practical question posed by most CEOs is... "Exactly how much will this cost me?" The lack of a definitive answer to that question has been a barrier to adoption, as well as a source of genuine concern among most business executives.

So, there have been numerous studies aimed at determining precisely what the costs and benefits of CMM implementation are. These have been conducted primarily in large, or leading edge organizations (these are best summarized in McGibbon, 1999). However, because such businesses are materially different both in their products and their processes, they tend to start from a different point and they have different requirements than the average small IT shop. So the question remains, "what are the factors and exactly how involved and costly is it to implement CMM in a conventional IT setting?" That is what we are attempting to answer with this research.

\section{Introduction}

oftware Engineering Institute's (SEI) Capability Maturity Model (CMM) is among the best-documented software process improvement (SPI) models from the standpoint of cost and benefit. Ever since it was introduced an assortment of reports and papers have been circulated that discuss its effect on business performance. In concept CMM embodies state-of-the-art best practices, the end-result of which is much improved 
organizational efficiency and effectiveness. These gains can be intangible as well as bottom line. Brodman (1995) reports on many non-measurable benefits from such practices. These include... "Improved morale by the developers increased respect for software from organizations external to software and less required overtime" (quoted in McGibbon, 1999). Brodman notes that some organizations looked at benefits from CMM not just in financial terms, but in terms of being more competitive (cheaper and better), improved customer satisfaction (fewer post release problems in the software) and more repeat business from their customers (quoted in McGibbon, 1999).

Herbsleb (1994) provided statistical results as reported for thirteen organizations to demonstrate the expected value of CMM-based Software Process Improvement. His findings were primarily focused on Level 2 and Level 3 organizations. They show gains in productivity due to... "Better requirements elicitation, better software management, and incorporation of a software reuse program. Gains in early detection of defects and reductions in calendar time were primarily attributed to reuse" (Hersleb, 1994). The Boeing Space Transportation Systems (STS) Defense and Space Group reported that improved software processes detected nearly $100 \%$ of all defects. Although this increased the design effort by $25 \%$ (4\% of total development time), it reduced rework during testing by $31 \%$ (of total development time). So a $4 \%$ increase in effort returned a $31 \%$ reduction in rework resulting in a 7.75:1 ROI (Yamamura and Wigle, 1997). Raytheon characterized the benefit of their improvement program by differentiating their costs into the categories of doing it right the first time versus the cost of rework. Based on their process improvement program, Raytheon was able to report that it had eliminated $\$ 15.8$ million in rework in less than 5 years (McGibbon, 1999).

These reports of success are encouraging. Nevertheless, as we said earlier, the problem is that most of them originate in organizations that work much closer to the leading edge than conventional IT firms. So the evidence of their efficacy tends to be negated somewhat (at least in the eyes of the traditional IT manager) by the fact that the projects on which they are based are not typical of common day-to-day operation. What's been missing to this point is a simple study of the practical cost of CMM deployment in a conventional IT organization. The objective of this research is to characterize that more precisely.

\section{Rationale for This Research}

We believe that the findings from this research will provide useful knowledge because it will address the most common question that upper level managers ask when such a project is proposed... "What's the investment picture look like?" This is particularly germane now because in these uncertain times companies want to know the value proposition of SPI before they begin committing funds to it (KPMG, 2001). For an increasing number of executive and financial officers, vague promises of productivity enhancements are no longer enough to justify budgets. "Executives want to know not just what they're getting for their IT dollar but why they should care (Lewis, 2001).

Nonetheless, IT organizations have traditionally not considered the cost of major project initiatives such as CMM before they leap into them. Michael C. Mah, editor of the IT Metrics Strategies newsletter says that... "Most SPI projects cost more than estimated, and most people aren't able to estimate correctly," he explains. "That drives [executives] to say, 'If you guys are always coming back to the well for more money, what's the value of something like this?" (Mayor, 2000) Robert Cawly, a senior VP for the Meta group summarizes the problem, "There is a lot of concern about maintaining the [IT] asset and doing a good job of managing IT resources, but you're never going to save your way to prosperity. Companies need a way to characterize costs" (Mayor, 2000). Moreover, this must be expressed in a way that is meaningful to the executives who are ... "Holding the purse strings or driving the company's corporate vision." (Lewis 2001).

As a result, the name of the game has been to provide a practical quantification of the costs of deploying an SPI project that will meaningfully define the link between investment and risk" (Mayor, 2000). Strassmann believes that cost analysis is a very important aspect of appraisal. According to him, "Cost analysis is the correct analytical technique with which one can examine the uncertainty of business reengineering investment prior to implementation." He believes that "By making the costs of deployment more explicit, you create a framework for 
diagnosing, understanding and containing the inherent difficulties associated with technological and organizational innovation" (McGibbon, 1999).

CMM project costing is beholden to many aspects of the company context. And a one-size measure doesn't fit all circumstances (Berry, 2001). On the surface it seems like a simple thing to distinguish the cost of implementing a process improvement program (e.g., at the end of the project you tote up the bill). But the hard part is finding a meaningful basis for describing how that cost was generated. For instance, most estimates (sensibly) assume that the project will be implemented efficiently and effectively. But what usually happens, especially with something like SPI is that a lot of money is spent developing a process that is either not understood, or not followed properly (Skamarock, 2001). So... Understanding the effects of the variables that underlie implementation on the total cost of the project is imperative for success (Skamarock, 2001). Building a compelling cost model requires the demonstration of three things in particular (Kotler, 2001):

- Objectivity - Too often, companies rely heavily on impressions or opinions about the degree to which the one aspect of the project or another influenced the total outcome.

- $\quad$ Replicability - To demonstrate replicability, the research must be based on more than one project.

- Relevant Comparisons - the idea is to benchmark results against comparable projects. Thus comparing the results of a level five SPI project to implementing level two in a conventional company is inappropriate.

Moreover most experts agree that this perspective must center on long-term effort data, rather than snapshots of the project at any given point in time. Hackett Benchmarking \& Research argues that a strict short-term approach to costing is doomed. According to Skamarock (2001)... The values used to calculate costs fall into two categories: hard numbers, or real dollars spent; and soft numbers, the "we think " numbers. The soft numbers are usually associated with personnel investment (as compared to the cost of the equipment). Thus it makes sense, to look at cost in terms of the complete set of project categories and functions?

Nevertheless, Curtis (1995) points out that it is difficult to measure cost benefits from process improvements in immature organizations such as those we are targeting in this study, because immature organizations rarely have good data (DACS, 1999). Since conventional organizations (e.g., those at CMM level one moving to level two) are, the focus of this study, we felt that we had to take into account the fact that there would be very little reported operational data available. For this we turned to Violino (1997) who found that, the intangible, or indirect measures are needed to assess a company's real costs. Kosmo Kalliarekos, a partner at The Parthenon Group, says intangibles can be a huge factor (Skamarock, 2001). But he emphasizes that even the intangibles have to be quantified to be of any use. Doug Busch, Intel's CIO corroborates this... "One of the things we've concluded is that a large percentage of the benefit from IT is not measurable in straight financial terms" (Ambrosio, 2001). "Likewise however, studies should avoid adopting stovepipe valuation systems, where every function uses a different set of measures to further different goals. The result can be an organizational cacophony. Local, narrow metrics can give you diminishing returns" (Mayor, 2000). We attempted to embody all of this advice in our research design.

\section{Methodology: Measurement}

This presents the results of a four-month study of the cost of fully deploying a CMM Level Two project in a conventional IT organization. It was conducted as a joint collaboration between industry and academic researchers in a small, well-established specialty development shop in Southeast Michigan. The two CMM certification projects that provide the basis for the study are routine contract programming ventures, being carried out as part of the dayto-day business of that organization.

Using the recommendations of the literature, we built our measurement process around what we considered to be the correct metric for representing both the hard financial as well as intangible implementation costs. This measure is reported effort by category as defined by actual time spent performing the work. Humphrey outlines both the justification and the means for capturing descriptive data this way (in his book A Discipline for Software Engineering - Humphrey, 1995). The first step in Humphrey's process is to encapsulate and analyze how the individuals involved in the project spend their time. Basically this addresses two logical questions: First what 
activities do you perform? And second how much time do you spend on each activity? We employed Humphrey's engineering notebook concept as the specific mechanism to capture this. The purpose of this notebook is to provide a record and repository for all personal software engineering data. The engineer's notebook is used to log the time spent in each phase of the work. Participants note in this $\log$, the time they started working on a task, the time when they stopped the task, and any interruption time. By tracking time precisely, we are able to characterize the effort actually spent on the project tasks. A summary of these notebooks contains all of the detailing (for all tasks) of the:

- $\quad$ Activity- the name or designation of the task

- $\quad$ Purpose- where the task fits into project plan

- $\quad$ Date - e.g., the date the entry was made

- $\quad$ Start Time - the time work on a task was begun

- $\quad$ Stop Time- the time that work on a task ceased

- Interruption Time - time that was not spent on the task

- $\quad$ Delta Time - net time spent working in the task

- $\quad$ Comments - any relevant comments

The engineering notebooks belonging to each participant were then aggregated into an activity summary. This characterized the time committed to each project activity. The weekly activity summary contains the following items

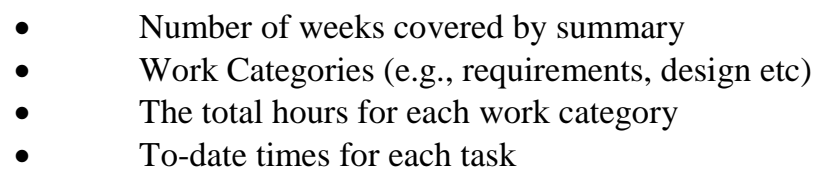

Using this approach we chronicled (via automated tool support) the actual time spent within each activity category for each individual participant over a four-month period. Participants noted down the time that they started working on a task, the time that they stopped the task, and any interruption time in the automated log (for example, an interruption would be a phone call, a brief break, or someone interrupting to ask a question). We believed that since interruption time is essentially random, ignoring these times would add a large random error into the time data and reduce estimating accuracy. By tracking time this precisely, we feel that were able to accurately allocate the effort spent on the project's deployment tasks.

\section{Methodology: Deployment Cost Categories}

Based on a thorough review of the literature we factored the categories of potential deployment cost into logical groupings. Using the time data assigned to each of these and captured in the engineering log for each participant we were able to calculate both a true hour effort and an estimated percentage of the total cost of deployment for each activity. The activity categories that we defined for this project are presented in Table One.

In concept these categories represent the three essential factors that underwrite the practical deployment of a CMM scheme: the necessary specification and documentation of the exact procedural steps as well as the assignment of responsibility and assessment methodology (e.g., in CMM terms the definition of the Common Features), the training required to establish a stable repeatable organizational process and last but certainly not least the effort needed to sell that process to the participants. The individual activity categories had actual time logged against them with the total effort assignment being the sum of each activity category (aggregated to a factor score as well as a total for the effort as a whole). This can be converted into cost data using the assigned salary values for the individual participants.

There are eight employees involved with the two projects in the reporting company. Each participated in this survey. As such, the reported effort approximates the full commitment of both project teams. The reporting period is for the entire length of the project from startup to the time of a CBA-IPI assessment. 
Table 1: Deployment Activity Category And Activity Descriptions

Category One: Training

1. Initial training effort (all process participants)

2. Initial training effort (development staff)

3. In-house on-going training effort required (to keep process stable)

4. Third party training effort (allocated for variables $1-3$ )

\section{Category Two: Procedural Definition}

1. Process flow/business flow specification of responsibility and procedures

2. Control flow and system level control assignment of responsibility

3. Data flow/reporting specification of procedures

4. Compliance/problem resolution specification of procedures

5. Actual project related process monitoring and control specification of procedures

6. Software Quality Assurance (SQA) specification of procedures

7. Configuration management (SCM) specification of procedures

\section{Category Three: Stakeholder management}

1. Decision maker awareness effort (e.g., communication with decision makers on necessity of use of CMM procedures)

2. User consciousness raising effort (e.g., communication with users on necessity of use of CMM procedures)

\section{Findings}

Our findings are summarized in Table Two (Please note: The detail for each of these categories is attached in Appendix One):

Table 2: Summary Of Actual Hour Investment By Activity Category

\begin{tabular}{|l|r|c|}
\hline \multicolumn{1}{|c|}{ Activity Category } & Hours & Percent \\
\hline CMM Process Flow Specification & 91.50 & $19.90 \%$ \\
\hline CMM Control Flow Specification & 64.00 & $13.92 \%$ \\
\hline CMM Data Flow Specification & 53.00 & $11.53 \%$ \\
\hline Decision Maker Management & 122.75 & $26.70 \%$ \\
\hline Product Related Process Assurance Activity & 102.50 & $22.29 \%$ \\
\hline Initial Training & 16.00 & $3.48 \%$ \\
\hline On going training & 10.00 & $2.18 \%$ \\
\hline & & \\
\hline TOTAL & $\mathbf{4 5 9 . 7 5}$ & $100 \%$ \\
\hline
\end{tabular}

Quite logically the majority of the time spent on this project is in the actual tailoring of the six Key Process Areas (KPA) of level two CMM to the requirements of the setting. To implement these KPAs properly, the details of the execution and accountability structure (process and control flow) must be precisely and explicitly defined and the means for verifying implementation (e.g., the reporting/data elements) aligned with the measurement and reporting structure of the rest of the organization. This universal set of requirements in essence satisfies the institutionalization factors expressed in the four common features of the model (commitment and ability to perform, measurement and verifying implementation). As such we found that an executive manager can expect to devote 45.4 percent of the actual project time to engineering the exact process that embodies the level Two KPAs within the particular organizational situation. 
Furthermore, (not surprisingly) because of the change in organizational structure that the imposition of a new approach implies, the next largest part of the project (26.7 percent) is devoted to bringing the managers responsible for the implementation into the process. It is well understood (in the literature... Gibbon, 2001 for instance) that one of the primary causes of failure in CMM projects is the lack of support/buy-in from the line executives responsible for managing and enforcing the KPAs. So, there is a fundamental necessity to set-aside time to bring these people solidly on board. This essential function is more explicitly described in the literature of human resource motivation. But it generally revolves around obtaining organization-wide feedback for the purpose of finetuning the procedures as well as obtaining personal commitment.

The next largest category (22.3 percent) represents the actual time spent insuring that the process was in fact properly followed and that appropriate corrective action took place. The fact that the actions taken to execute the actual project only represent a fifth of the total investment is by far the most surprising outcome of this study. We believe that it is an important piece of information in that it suggests that (for organizations of this type) the real expense of a properly instituted CMM project lies in a careful and thorough set-up phase rather than in its actual execution under best practice control. This has considerable implications for executives contemplating a CMM deployment since (based on our findings) it suggests that IF the organization can handle the set-up cost the actual project execution is a relatively minor expense item. Which means that there is a long period where the benefits in enhanced performance will by far outweigh the costs. This is to some extent substantiated by the findings of studies in advanced organizations (specifically Yamamura, 1997), which indicate that once the initial investment is made there is a significant return on investment over the lifecycle of the project.

The other surprising finding of this study was the inconsequential amount of time spent on training (5.7 percent). Given the need to bring employees up-to-speed on the new policies, procedures and expectations of the model this would seem to be contradictory. We believe, however that this might be accounted for by the fact that all of the employees in this setting are skilled, professional software engineers. Since this also describes the composition of the staff in most specialty development shops, there is some cause to assume that these places might be particularly fruitful ground for CMM deployments.

Therefore in summary, if you assume that the setup phase of a level two CMM project is composed of the tailoring and executive buy-in activity, the amount of effort that an organization can reasonably be expected to devote to achieving that status amounts to 72.1 percent (or most) of the total investment. Since this takes place in the early stages of the process these costs are indeed as everybody suspected "up-front". However, following that initial investment in time the actual implementation/operation of the project is comparatively minimal.

\section{Conclusion}

We believe that the results of this study add to the overall understanding of the costs of instituting CMM in IT organizations. Furthermore we feel that we can demonstrate that our findings fit well with prior results (obtained in larger, more advanced organizations) in that both our study and earlier studies have substantiated the notion that the costs of CMM deployment follow a rapidly descending dynamic curve illustrated in Figure One from high investment at setup to minimal cost in long-term use.

Moreover we feel that this is useful knowledge since conventional business executives generally do not understand the investment dynamics associated with the implementation of process improvement projects. The results of this study indicate that his group must keep in mind that most of the investment is "up-front", since the cash flow of a CMM implementation project will inevitably look like a one-way street in the early stages. It is apparent however that over a long period of use there will be considerable return on that investment obtained from the improvement to the performance of the basic functions of the organization.

The data reported here represents a front-to-back description of the actual effort involved in instituting CMM level two in a small, typical software development organization. We believe that the replication and further corroboration of earlier observed phenomenon, obtained in very large, well-funded studies, both validates our own 
findings as well as supports the belief that CMM is cost effective in the long term. We hope that this adds to the confidence of any business interested in making that commitment.

Figure 1: Progression Of Costs Throughout The Lifecycle

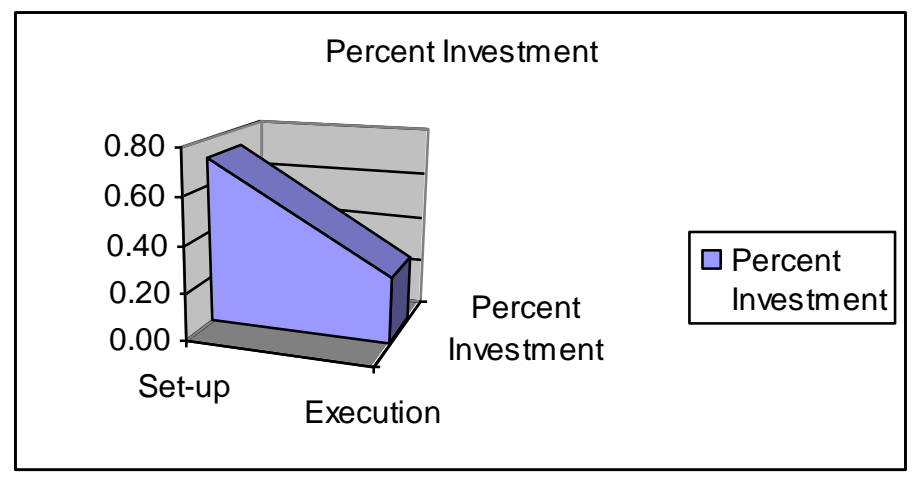

\section{References}

1. $\quad$ Ambrosio, Johanna, "What to Count?", Computerworld, July 16, 2001.

2. Berry, John, “A Short Term ROI Approach Won’t Pay”, Internet Week, September 10, 2001.

3. Berry, John, "IT ROI Metrics Fall Into Four Groups", Internet Week, July 16, 2001.

4. Broadman JG, Johnson DL, "Return on Investment from Software Process Improvement Measured by US Industry", Software Process - Improvement and Practice, July 1995.

5. $\quad$ Curtis W., "Building a Cost-Benefit Case for SPI", 7th SEPG Conference, Boston, 1995.

6. Hamblen, Matt, "Get Payback", Computerworld, January 1, 2001.

7. Hersleb, J, Zubrow D, Siegel J, Rozum J, Carlton A, "Software Process Improvement: State of the Payoff", American Programmer, v7 no.9, September, 1997.

8. Humphrey, Watts, "The Personal Software Process", TR CMU/SEI - 2000-022, Carnegie-Mellon University, 2000.

9. Keefe, Patricia, "Take a Bold Step”, Computerworld, July 30, 2001.

10. Koller, Mike, “Accurate ROI Requires Impartiality”, Internet Week, September 25, 2001.

11. Kotler, Tony, "A Hard Lesson in ROI”, Line56.com, July 12, 2001.

12. "KPMG Technology and Services Group", web site at www.kpmg.ca, accessed July 2002.

13. Lewis, David, "Demand for ROI Rises", InternetWeek, March 27, 2001.

14. Mayor, Tracy, "Value Made Visible", CIO, May 1, 2000.

15. McGibbon, Thomas, "A Business Case for Software Process Improvement Revised", DoD Data Analysis Center for Software (DACS), 1999.

16. Miller, Dan, "The ROI on CRM", The Industry Standard, August 6, 2001.

17. "Software Engineering Institute", web site at www.sei.cmu.edu. Accessed July 2002.

18. Skamarock, Anne, "Quantifying ROI", NetworkWorldFusion, July 9, 2001.

19. Strassman, P.A., "The Business Value of Computers", The Information Economics Press, New Canaan, Connecticut, 1990.

20. Violino R, "Measuring Value: Return on Investment", Information Week, No. 637, (June 30, 1997) pp. 36-44.

21. Yamamura G, Wigle GB, "SEI CMM Level Five: For the Right Reasons", Volume 10\#8, August 1997 
Appendix

Detail Of Results Reported In Table 2

\begin{tabular}{|c|c|c|c|c|c|c|c|c|}
\hline & $\begin{array}{c}\text { Initial } \\
\text { Training }\end{array}$ & $\begin{array}{l}\text { On going } \\
\text { Training }\end{array}$ & $\begin{array}{l}\text { Process Flow } \\
\text { Specification }\end{array}$ & $\begin{array}{l}\text { Control Flow } \\
\text { Specification }\end{array}$ & \begin{tabular}{|c|} 
Data Flow \\
Specification
\end{tabular} & $\begin{array}{l}\text { Product } \\
\text { Related } \\
\text { Activity }\end{array}$ & $\begin{array}{c}\text { Decision } \\
\text { Maker } \\
\text { Management }\end{array}$ & Total \\
\hline Company & 8.00 & 5.00 & 49.50 & 29.00 & 31.00 & 91.75 & 34.25 & 248.50 \\
\hline Customers & 0.00 & 0.00 & 42.00 & 25.00 & 22.00 & 0.75 & 67.00 & 156.75 \\
\hline \multirow[t]{2}{*}{ Third Parties* } & 8.00 & 5.00 & 0.00 & 10.00 & 0.00 & 10.00 & 21.50 & 54.50 \\
\hline & 16.00 & 10.00 & 91.50 & 64.00 & 53.00 & 102.50 & 122.75 & 459.75 \\
\hline $\begin{array}{c}* \text { Third party } \\
\text { based activity }\end{array}$ & $\begin{array}{c}C M M \\
\text { Training for } \\
\text { staff }\end{array}$ & \begin{tabular}{|} 
Training \\
required to \\
keep process \\
stable
\end{tabular} & $\begin{array}{c}\text { Business flow } \\
\text { modeling }\end{array}$ & $\begin{array}{c}\text { Responsibility } \\
\text { and system } \\
\text { level control } \\
\text { documentatio } \\
n\end{array}$ & $\begin{array}{c}\text { Data flow } \\
\text { documentatio } \\
n\end{array}$ & \begin{tabular}{|c|} 
Primarily \\
Development \\
of the SRS
\end{tabular} & \begin{tabular}{|c|} 
Communicati \\
on with \\
decision \\
makers on \\
necessity of \\
use of CMM \\
procedures
\end{tabular} & \\
\hline
\end{tabular}

Notes 